
\title{
R Reserach S Suare \\ Heterogeneous Health Classes for Older Adults in China: Based on Multidimensional Health
}

\author{
Yi Hu
}

Southern Medical University

Zhenyu Wang

Central South University

Zhihan Liu

Central South University

Bei Li ( 0 45510307@qq.com )

Southern Medical University

\section{Research Article}

Keywords: Multidimensional health, Latent Class Analysis, Older adults, Health profiles

Posted Date: May 13th, 2021

DOl: https://doi.org/10.21203/rs.3.rs-493871/v1

License: (c) (1) This work is licensed under a Creative Commons Attribution 4.0 International License. Read Full License 


\section{Abstract \\ Background}

The concept of health is multidimensional, so the evaluation of the health status of the elderly and the analysis of the influencing factors should also be multidimensional. This study aims to identify the heterogeneity of the health status of Chinese older adults.

\section{Methods}

Data were derived from the China Health and Retirement Longitudinal Study (CHARLS) $2015(n=4190)$. Latent class analysis was performed based on 6 health indicators, including self-reported health status, the number of chronic diseases, activity of daily living (ADL), depressive symptoms, cognitive ability, and social activities participation. Logistic regression was used to analyze the predictive effect of demographic characteristics variables on different health classes of older adults.

\section{Results}

Three health latent classes were identified and labeled as Relatively Healthy Group $(n=1003,23.94 \%)$, Multiple Chronic Conditions with High Social Participation Group $(n=1744,41.62 \%)$, and Frail Group ( $n=$ $1443,34.44 \%)$. The health status of Chinese older adults is not optimistic. In particular, our study found that older adults with multiple chronic diseases had the highest social participation frequency among the three classes. When Frail Group was the reference, the logistic regression results showed that older-aged adults, those without spouses, those with low educational level, and those with agricultural household registration were more likely to be Frail Group.

\section{Conclusion}

There is heterogeneity in the health status of older adults, and identifying the health status of older adults from a multidimensional health perspective can help provide better health services to them based on health latent classes.

\section{Background}

Compared with developed countries, China shows a unique aging pattern of "getting old before getting rich", and aging is occurring there on a larger scale and at a more rapid pace, creating a heavier dependency burden [1]. The aging of the population, not only leads to significant health transitions and extensive utilization of healthcare resources but may also have an impact on social security systems such as health care and pension systems [2]. Meanwhile, more than 50 percent of people aged 75 and older have multiple chronic diseases [3], it is expected that more older people will have a greater need for 
medical and long-term care services. However, due to the variability and interdependence of health conditions, the health status of older people varies greatly [4]. Realizing the goal of "aging with quality care, aging with responsive support" has become increasingly challenging.

The health status of the elderly is basic for geriatric work and geriatric service practice. In order to scientifically predict the future demand for care services for the elderly population and to construct a reasonable geriatric health policy system, the health status of the elderly needs to be comprehensively and accurately assessed [5]. The World Health Organization (WHO) has defined health as a state of complete physical, mental, and social well-being, suggesting that health is a multi-layered concept and that the assessment of the health status of older people requires the use of multiple health measures [6]. Thus, there is growing concern about the complex health conditions of the growing elderly population and their different need for health services $[7,8]$.

Predicting the health of older people usually involves looking at independent relationships between indicators of chronic disease, functional capacity, mental health, cognition, personal eating habits, and social and family support [9-14]. While these are valid predictors of outcomes, they tend to describe a single dimension of health. However, the health status of older adults is a synergistic combination of multiple health dimensions, and because of the high heterogeneity of this group the approach to "older people" as a single group is not helpful if one wishes to understand and improve health care use [15]. Different groups of older people actually consume a disproportionate and sometimes inappropriate share of health services due to their own heterogeneity [4].

Multiple dimensions of health indicators interact to influence the overall health status, resulting in a high degree of heterogeneity in the health status of older people. Thus, over the past three decades, a recognition of the need for more sophisticated models that can differential between various levels of heterogeneity [16], and some studies are beginning to differentiate and assess the needs and preferences of older people through a person-centered research approach. As a"person-centered" approach, the latent class analysis aims to identify subgroups of people who share common characteristics in such a way that people within the subgroups have a similar scoring pattern on the measured variables [17], and therefore present several advantages over classical statistical models $[18,19]$ : the focus of LCA is on relationships between individuals, rather than other statistical methods such as regression analysis and factor analysis, which focus on relationships between variables; LCA's classification is model-based and statistical diagnostic tools exist to assess the quality of the classification. In geriatrics, LCA has been used to test for heterogeneity in the health of older people in order to test the validity of some measures [20].

Based on multidimensional health, previous researches showed that older people were identified and labeled as"Lacking Socialization", "High Comorbidity" "Severe Disability", and "Relative Health" [7]. And Wild et al. [15] believed that the difficulties experienced by older people are determined not only by their illness but also by their psychosocial condition, more homogeneous subgroups should be defined according to the bio-psycho-social needs and functions of the elderly. In addition, latent class analysis 
have been applied to distinguish or identify male elderly health service use [21], chronically ill patients in primary care [22] as well as to the cognitive functioning among depressed older adults without dementia [23]. Clearly, LCA can be a useful approach to studying older people's health.

Despite the attention and year-on-year increase in worldwide research on health heterogeneity in older people, the studies on the heterogeneous and multidimensional health groups of the elderly Chinese population by person-centered approaches remain limited [7]. Most of the existing studies start from the perspective of variables and use cluster analysis methods, without taking into account individual differences, and lack in-depth studies that distinguish different health latent classes of elderly people [24]. Additional research is needed on multidimensional health indicators and the high heterogeneity of their health status among older Chinese.

Our primary focus of this study is to investigate multidimensional health in late old age. Therefore, using data from the China Health and Retirement Longitudinal Study, we used the LCA approach to analyze the health latent class of older people in China, aiming to help managers understand the variability in the health status and health service needs of older people, and to develop targeted healthcare interventions to adjust resource allocation and facilitate healthcare resource planning.

\section{Methods}

\section{Data Sources and Study Population}

The data utilized for this study were derived from the China Health and Retirement Longitudinal Study (CHARLS) 2015. CHARLS adopts Probability Proportional to Size sampling, and aims to collect a highquality nationally representative sample of Chinese residents aged 45 and older to serve the needs of scientific research on older adults. Detailed information about the CHARLS design strategy has been described elsewhere, the ethical approval of data collection was from the Biomedical Ethics Review Committee of Pecking University (IRB00001052-11015) [25]. Variable screening and data cleaning were performed according to the needs of the study, and after removing the non-elderly sample and the sample with missing key variables, 4190 older adults ${ }^{3} 60$ years old were included as the study population for analysis. Among them, 1962 (46.8\%) were male and 2228 (53.2\%) were female; 2724 (65.0\%) were aged 60-69 years, 1211 (28.9\%) were aged $70-79$ years, and 255 (6.1\%) were aged $\geq 80$ years; $672(16.0 \%)$ without spouse, 3518 (84.0\%) with spouse; 997 people (23.8\%) had no formal education, 1995 people $(47.6 \%)$ had graduated from elementary school, 745 people $(17.8 \%)$ had graduated from middle school, 390 people (9.3\%) had graduated from high school(including vocational school), 63 people (1.5\%) had graduated from college and above; 3006 people $(71.7 \%)$ had agricultural household registration, 1184 people $(28.3 \%)$ had non-agricultural household registration.

\section{Variable Definitions}

In this study, six indicators were selected from the CHARLS data for identifying latent classes of multidimensional health in older adults, including self-reported health status, the number of chronic 
diseases, activity of daily living (ADL), depressive symptoms, cognitive ability, and social activities participation. Among them, self-reported health status, number of chronic diseases and social activities participation were self-reported. Self-assessed health status was evaluated using 5 categories ( $1=$ Very good, $2=$ Good, $3=F a i r, 4=$ Poor, $5=$ Very poor). The number of chronic diseases was integrated into a multi categorical variable based on the number of chronic diseases self-reported by respondents, with 1 indicating no chronic diseases, 2 indicating having 1 chronic disease, and 3 indicating having 2 or more chronic diseases. The notion of social activities participation was operationalized by asking the question "Have you done any of these activities in the last month?" with 0 indicating no social activities participation and 1 indicating having social activities participation.

ADLs were assessed with the ADL scale[26]. The scale includes 6 items such as bathing, eating, getting in or out of bed, dressing, using the toilet, and controlling urination and defecation. The response scale contained 4 options: 1) No, I don't have any difficulty; 2) I have difficulty but can still do it; 3) Yes, I have difficulty and need help; and 4) I cannot do it. The respondents were classified as ADL independent if they do not need help with all items, whereas those who needed help with at least one item were regarded as ADL impairment.

Depressive symptoms were assessed using the 10-item Center for Epidemiological Studies Depression Scale (CES-D-10) [27]. The survey respondents were asked about their feelings and behaviors over the past week. According to the level of depressive symptoms reflected by the items, they were assigned a score of 0-3 points, giving a total score of 0-30 points. The higher the score, the more severe the depressive symptoms. Generally, a cutoff score $\geq 10$ is considered to indicate the respondent having depressive symptoms [28].

Cognitive ability was measured using the brief Community Screening Instrument for Dementia (CSI-D) [29]. The scale consists of two parts: the interviewee part (7 items with a score of 0-9) and the informant part (6 items with a score of 0-6). The scale score is the interviewee part score minus the informant part score and ranges from -6 to 9 , with scores of 4 or less highly suggestive of dementia.

Demographic variables such as gender, age, marital status, education level, and household registration were included as control variables.

\section{Statistical Analysis}

The Latent Class Analysis (LCA) method is used to deal with the classification of the multi-dimensional health groups of the elderly. As a person-centered approach, the goal of LCA is to reveal a minimal number of unobserved groups of individuals in terms of health latent classes to fully explain the associations between observed health dimensions, ultimately grouping individuals into categories, each containing individuals that are similar to each other but different from other categories [30]. The Akaike Information Criterion (AIC), Bayesian Information Criterion (BIC), and adjusted BIC (aBIC) are used as tests of model fit for latent class analysis, and a smaller index indicates a better model fit [31]. Entropy values were used to assess the accuracy of the model classification, with Entropy values ranging from 0 
to 1. Lubke and Muthén stated that Entropy $<0.60$ corresponds to more than $20 \%$ of individuals with classification errors; Entropy $=0.80$ indicates a classification accuracy of more than $90 \%$ [32]. The difference in fit between $\mathrm{k}$ and $\mathrm{k}-1$ profile models was compared using Lo-Mendell-Rubin adjusted likelihood ratio test (LMR) and the bootstrapped likelihood ratio test (BLRT), and the significant $p$ value $(p<0.05)$ indicating that the $\mathrm{k}$ profile model significantly outperformed the $\mathrm{k}-1$ profile model. Data were analyzed using Mplus8.3.

Then, analysis of variance (ANOVA) was performed to test whether there were differences in demographic characteristics across classes, and multivariable logistic regression was used to analyze the predictive effect of demographic characteristics variables on different health classes of older adults.

\section{Results}

\section{Latent health classes for older adults}

All six health indicators are used as explicit indicators, and the number of health latent classes is sequentially increased to estimate the fit of the model. A comparison of LCA model fit statistics was shown in Table 1. The 5-class model obtained the smallest AIC, BIC was smallest at 3-class, and aBIC was smallest at 4-class. Furthermore, the Entropy value reached the highest value of 0.629 in 3-class, indicating that 3-class was the most accurate model. The LMR was not statistically significant at 4-class, indicating there was no significant improvement in model fit between 3- and 4-class. Therefore, the study adopted the three-class LCA model.

Table 1

the model fit statistics for 1- to 6-class models

\begin{tabular}{|c|c|c|c|c|c|c|c|c|}
\hline Model & k & AlC & $\mathrm{BIC}$ & $\mathrm{aBIC}$ & Entropy & LMR & BLRT & $\begin{array}{l}\text { Classes } \\
\text { Probability }\end{array}$ \\
\hline 1 & 10 & 37234.226 & 37297.630 & 37265.855 & - & - & - & 1 \\
\hline 2 & 21 & 36011.218 & 36144.367 & 36077.638 & 0.558 & $\star \star \star ~$ & $\star \star \star ~$ & $0.548 / 0.452$ \\
\hline 3 & 32 & 35885.447 & 36088.342 & 35986.659 & 0.629 & $\star \star \star ~$ & $\star \star \star ~$ & $\begin{array}{l}0.239 / \\
0.344 / 0.416\end{array}$ \\
\hline 4 & 43 & 35819.270 & 36091.911 & 35955.275 & 0.519 & 0.8535 & $\star \star \star$ & $\begin{array}{l}0.167 / \\
0.429 / \\
0.138 / 0.266\end{array}$ \\
\hline 5 & 54 & 35810.297 & 36152.682 & 35981.092 & 0.553 & 1.0000 & $\star \star \star ~$ & $\begin{array}{l}0.137 / \\
0.277 / \\
0.117 / \\
0.116 / 0.353\end{array}$ \\
\hline $\begin{array}{l}\text { Note: } 1 \\
\text { Criteric } \\
\text { Bootst }\end{array}$ & & $\begin{array}{l}\text { ber of paran } \\
\text { adjusted } B I \\
\text { ikelihood } R\end{array}$ & $\begin{array}{l}\text { ers. 2. AIC, } \\
\text { MR, Lo-M } \\
\text { Test. 3. }\end{array}$ & $\begin{array}{l}\text { aike Inform } \\
\text { dell-Rubin } \\
=0.001 \text {. }\end{array}$ & $\begin{array}{l}\text { on Criteri } \\
\text { iusted lik }\end{array}$ & $\begin{array}{l}\text { : BIC, Ba } \\
\text { hood ral }\end{array}$ & $\begin{array}{l}\text { sian I. } \\
\text { test ; }\end{array}$ & $\begin{array}{l}\text { Prmation } \\
R T,\end{array}$ \\
\hline
\end{tabular}


Based on the identification of the latent health profiles, the conditional health indicator probabilities $(\lambda)$ were obtained, as shown in Table 2, based on which the characteristics of each category were further analyzed and labeled.

The first class ( $n=1003,23.94 \%$ ) was characterized by a higher probability of having a fair self-reported health status $(\lambda=0.574)$, no chronic disease $(\lambda=0.448)$, having 1 chronic disease $(\lambda=0.552)$, ADL independent $(\lambda=0.992)$, no depressive symptoms $(\lambda=0.772)$, no dementia $(\lambda=0.638)$, indicating that the overall health of the older adults in this class was better. Thus, we labeled this class of older adults as "Relatively Healthy" group. The second group $(n=1744,41.62 \%)$ was prone to having the highest probabilities for having $\geq 2$ chronic diseases $(\lambda=0.898)$, no dementia $(\lambda=0.689)$, and social activities participation $(\lambda=0.609)$ among three classes. Older adults in class 2 were better than those in class 3 but worse than those in class 1 , on indicators of self-reported health status, the activity of daily living, and depressive symptoms. This class was labeled "Multiple Chronic Conditions with High Social Participation" group. The third class tended to have higher probabilities for poor self-reported health status $(\lambda=0.494)$, having $\geq 2$ chronic diseases $(\lambda=0.882)$, ADL impairment $(\lambda=0.203)$, having depressive symptoms $(\lambda=0.767)$, having dementia $(\lambda=0.677)$, no social activities $(\lambda=0.591)$, indicating that this group has the worst health status among the 3 groups. This group of 1443 participants has been labeled the "Frail Group". 
Table 2

conditional probabilities per health latent class for older adults

\begin{tabular}{|c|c|c|c|c|}
\hline & & $\begin{array}{l}\text { Class } 1 \\
(n= \\
1003)\end{array}$ & $\begin{array}{l}\text { Class } 2 \\
(n= \\
1744)\end{array}$ & $\begin{array}{l}\text { Class } 3 \\
\\
(n= \\
1443)\end{array}$ \\
\hline \multirow[t]{5}{*}{ Self-Reported Health Status } & Very good & 0.187 & 0.070 & 0.005 \\
\hline & Good & 0.214 & 0.101 & 0.010 \\
\hline & Fair & 0.574 & 0.616 & 0.303 \\
\hline & Poor & 0.024 & 0.181 & 0.494 \\
\hline & Very poor & 0.001 & 0.032 & 0.188 \\
\hline \multirow{3}{*}{$\begin{array}{l}\text { The number of chronic } \\
\text { diseases }\end{array}$} & No chronic diseases & 0.448 & 0.000 & 0.025 \\
\hline & Having 1 chronic disease & 0.552 & 0.102 & 0.093 \\
\hline & $\begin{array}{l}\text { Having } 2 \text { or more chronic } \\
\text { diseases }\end{array}$ & 0.000 & 0.898 & 0.882 \\
\hline \multirow[t]{2}{*}{ ADL } & ADL independent & 0.992 & 0.977 & 0.797 \\
\hline & ADL impairment & 0.008 & 0.023 & 0.203 \\
\hline \multirow[t]{2}{*}{ Depressive symptoms } & No depressive symptoms & 0.772 & 0.756 & 0.233 \\
\hline & Having depressive symptoms & 0.228 & 0.244 & 0.767 \\
\hline \multirow[t]{2}{*}{ Cognitive ability } & No dementia & 0.638 & 0.689 & 0.323 \\
\hline & Having dementia & 0.362 & 0.311 & 0.677 \\
\hline \multirow[t]{2}{*}{ Social activities participation } & No social activities & 0.500 & 0.391 & 0.591 \\
\hline & Having social activities & 0.500 & 0.609 & 0.409 \\
\hline
\end{tabular}

\section{Differential Analysis Of Health Latent Class For Older Adults}

The chi-square test was used to investigate whether the distribution of latent classes of multidimensional health among older adults with different demographic characteristics was statistically significant, and the results are shown in Table 3. As shown in Table 3, the differences in health latent classes among the elderly groups by gender, age, marital status, education level, and household registration were statistically significant $(P<0.05)$. Older adults of all genders, ages, and household registration were most distributed in class 2; older adults with spouses were most distributed in class 2 while those without spouses were 
more distributed in class 3; among education levels, older adults with all education levels were most distributed in class 2 except for those with no formal education who were most distributed in class 3 .

Table 3

Difference among health latent class with demographic characteristics

\begin{tabular}{|c|c|c|c|c|c|}
\hline & & $\begin{array}{l}\text { Class } 1 \\
{[\mathrm{n}(\%)]}\end{array}$ & $\begin{array}{l}\text { Class } 2 \\
{[\mathrm{n}(\%)]}\end{array}$ & $\begin{array}{l}\text { Class } 3 \\
{[\mathrm{n}(\%)]}\end{array}$ & $\begin{array}{l}P \\
\text { value }\end{array}$ \\
\hline \multirow[t]{2}{*}{ Gender } & Male & 493(25.1) & $843(43.0)$ & 626(31.9) & 0.005 \\
\hline & Female & $510(22.9)$ & $901(40.4)$ & $817(36.7)$ & \\
\hline \multirow[t]{3}{*}{ Age(year) } & $60 \sim 69$ & $693(25.4)$ & 1111(40.8) & $920(33.8)$ & 0.011 \\
\hline & $70 \sim 79$ & 246(20.3) & $523(43.2)$ & $442(36.5)$ & \\
\hline & $\geq 80$ & $64(25.1)$ & 110(43.1) & 81(31.8) & \\
\hline \multirow[t]{2}{*}{ Marital status } & Without spouse & 159(23.7) & 241(35.9) & $272(40.5)$ & 0.001 \\
\hline & With spouse & $844(24.0)$ & 1503(42.7) & 1171(33.3) & \\
\hline \multirow[t]{5}{*}{ Education level } & No formal education & $231(23.2)$ & $330(33.1)$ & $436(43.7)$ & $\begin{array}{l}< \\
0.001\end{array}$ \\
\hline & Elementary school & 495(24.8) & 793(39.7) & 707(35.4) & \\
\hline & Middle school & $179(24.0)$ & $349(46.8)$ & $217(29.1)$ & \\
\hline & $\begin{array}{l}\text { High school(including } \\
\text { vocational school) }\end{array}$ & $88(22.6)$ & 226(57.9) & $76(19.5)$ & \\
\hline & College and above & 10(15.9) & $46(73.0)$ & $7(11.1)$ & \\
\hline \multirow[t]{2}{*}{$\begin{array}{l}\text { Household } \\
\text { registration }\end{array}$} & $\begin{array}{l}\text { Agricultural household } \\
\text { registration }\end{array}$ & $751(25.0)$ & 1097(36.5) & 1158(38.5) & $<.001$ \\
\hline & $\begin{array}{l}\text { Non-agricultural household } \\
\text { registration }\end{array}$ & $252(21.3)$ & $647(54.6)$ & $285(24.1)$ & \\
\hline
\end{tabular}

A multicategorical logistic regression was used to analyze the effect of demographic variables on the health latent class of older adults, using the latent classification results as the dependent variable. The results are shown in Table 4. Using the Frail Group (Class 3 ) as a reference, compared with the Relatively Healthy group (Class 1) and the Multiple Chronic Conditions with High Social Participation group (Class 2), the health latent class of older adults were found to be significantly influenced by marital status, educational level, and household registration. The regression results showed that older adults aged $70-$ 79 years were 0.687 times more likely to be Class 1 than Class 3 , while those without spouse, having no 
formal education, had graduated from elementary school, had graduated from junior high school, and having agricultural household registration were more likely to be Class 3 .

Table 4

Multicategorical Logistic Regression Analysis of Health Latent Classes

\begin{tabular}{|c|c|c|c|c|c|}
\hline & & \multicolumn{2}{|l|}{ Class 1} & \multicolumn{2}{|l|}{ Class 2} \\
\hline & & OR & $95 \% \mathrm{Cl}$ & $O R$ & $95 \% \mathrm{Cl}$ \\
\hline Gender(Female) & Male & 1.127 & $\begin{array}{l}0.944 \\
\tilde{1} \\
1.344\end{array}$ & 0.983 & $\begin{array}{l}0.841 \\
\tilde{1} \\
1.148\end{array}$ \\
\hline \multirow[t]{2}{*}{$\operatorname{Age}($ year $)(\geq 80)$} & $60 \sim 69$ & 0.924 & $\begin{array}{l}0.644 \\
\tilde{1} \\
1.325\end{array}$ & 0.874 & $\begin{array}{l}0.632 \\
\tilde{1} 1.209\end{array}$ \\
\hline & $70 \sim 79$ & $0.687^{*}$ & $\begin{array}{l}0.473 \\
\tilde{0} \\
0.997\end{array}$ & 0.865 & $\begin{array}{l}0.621 \\
\tilde{1} \\
1.204\end{array}$ \\
\hline Marital status(With spouse) & Without spouse & 0.889 & $\begin{array}{l}0.708 \\
\tilde{1} \\
1.115\end{array}$ & $0.718^{*}$ & $\begin{array}{l}0.586 \\
\tilde{0} \\
0.880\end{array}$ \\
\hline \multirow[t]{4}{*}{ Education level(College and above) } & No formal education & 0.443 & $\begin{array}{l}0.163 \\
\tilde{1} \\
1.207\end{array}$ & $0.196^{*}$ & $\begin{array}{l}0.086 \\
\tilde{0} \\
0.449\end{array}$ \\
\hline & Elementary school & 0.558 & $\begin{array}{l}0.207 \\
\tilde{1} \\
1.499\end{array}$ & $0.268^{\star}$ & $\begin{array}{l}0.119 \\
\tilde{0} \\
0.606\end{array}$ \\
\hline & Middle school & 0.613 & $\begin{array}{l}0.226 \\
\tilde{1} \\
1.662\end{array}$ & $0.336^{\star}$ & $\begin{array}{l}0.147 \\
\tilde{0} \\
0.764\end{array}$ \\
\hline & $\begin{array}{l}\text { High school(including } \\
\text { vocational school) }\end{array}$ & 0.821 & $\begin{array}{l}0.296 \\
\tilde{2} \\
2.277\end{array}$ & 0.535 & $\begin{array}{l}0.230 \\
\tilde{1} \\
1.243\end{array}$ \\
\hline $\begin{array}{l}\text { Household registration(Non- } \\
\text { agricultural household registration) }\end{array}$ & $\begin{array}{l}\text { Agricultural household } \\
\text { registration }\end{array}$ & 0.841 & $\begin{array}{l}0.681 \\
\sim \\
1.039\end{array}$ & $0.548^{*}$ & $\begin{array}{l}0.549 \\
\tilde{0} \\
0.656\end{array}$ \\
\hline Note: ${ }^{\star} P<0.05$ & & & & & \\
\hline
\end{tabular}

\section{Discussion}

Using LCA, this study classified 4190 older adults with multidimensional health status into 3 classes: "relatively healthy group" (23.94\%), "multiple chronic conditions with high social participation group" (41.62\%) and "frail group" (34.44\%). Other researchers have analyzed the health latent classes of older adults by considering their physical, cognitive and psychological status and have identified 2-6 latent 
classes [6, 33, 34]. Ye et al. identified four latent health classes among 2981 Chinese older adults $\geq 65$ years of age, labeled as "Lacking Socialization"(10.4\%), "High Comorbidity" (16.7\%), "Severe Disability" (7.8\%), and "Relative Health" (65.1\%) [35].Although the latent classed obtained from different studies vary, this still suggests that there are differences in the distribution and characteristics of health status of older adults. In addition, consistent with other researchers' studies, this study found two groups of older adults with significantly different health status in the health latent classes, one group with higher levels of physical, psychological, and social health, and the other group with higher health risks in the opposite direction. However, the percentage of the "frail group" were higher than the "relatively healthy group", which indicates that the overall health level of Chinese older adults is poor and their health status is not optimistic.

In contrast to traditional studies that simply distinguish between healthy and unhealthy older adults, this study identified a highly neglected group, the "multiple chronic conditions with high social participation" group, and this potential group was the largest in this study. In this study, older adults in the "multiple chronic conditions with high social participation group" differed from those in the "relatively healthy group" mainly in the number of chronic diseases and the resulting slightly poorer self-rated health status, with no significant differences in ADLs, depression, and cognition between the two groups. This may have allowed this class to be overlooked in studies of the health status of older adults. Previous studies have found that people with chronic diseases often suffer from the negative effects of physical, psychological and social health caused by disease stigma, which leads to the increase of difficulty in disease self-management, low self-identity, avoidance of social activities, fear of the future and so on [36-38].But surprisingly, our study found that older adults with multiple chronic diseases had higher social participation frequency than the other two classes, which may be caused by two reasons. On the positive side, the elderly with multiple chronic diseases will have a stronger sense of self-management. They expect to maintain their mental and physical health through active exercise and social participation. Franke et al. interviewed highly active community-dwelling older adults, and found that most of them expressed self-confidence in self-efficacy, self-control and adaptability, even in the face of challenges such as chronic and acute diseases. They tend to deal with the deterioration of their health through longer time, higher intensity of exercise or higher frequency of social interaction, even as they sought to prove they were "healthy" and to dispel the stereotype that they were "old" [39]. Xu et al. also found that most of older adults with chronic diseases have a demand for services such as regular personalized home visits by the community and volunteers, and the provision of platforms for social participation [40]. At the same time, the elderly with multimorbidity also want to be treated as friends by their caregivers, so as to meet their social and psychological needs [41]. As a result, older adults with multiple chronic conditions are motivated to participate in social activities for the purpose of health self-management, which results in a higher level of social participation in this group of older people than in other older people. On the negative side, according to alienation theory, older adults can better maintain their physical health by reducing social activities [42], and participation in social activities may affect their adaptation to a peaceful old age life and become a risk factor for chronic disease in older adults[43]. In a 
reverse sense, the higher the frequency of social participation may lead to a higher incidence of chronic disease in this group of older adults.

Certain demographic characteristics are associated with health latent classes of the older adults. The older the age, the higher the probability of poor health. This conclusion is indisputable, since the risk of various diseases increases with age. Older adults without spouse are more likely to be "frail group". Many studies have reported the relationship between marital status and health, and in general, there is a positive relationship between having spouse and health, and the health status of widowed, unmarried and single populations is poor [44]. Then, low education level is the risk factor for the elderly to become "frail group", which is consistent with Liu et al [45].Higher educational level tends to imply higher socioeconomic status, and these people are more likely to adopt healthy lifestyles, have greater access to social resources for health promotion, and better understand and follow the instructions of their health care providers [46]. Household registration is also associated with the health status of older adults, with those who have an agricultural household registration being at greater health risk. For older adults with an agricultural household registration, if they live in rural areas, they have poorer access to medical resources and health service management than urban older adults [47]; if they live in cities, the relatively unfavorable living environment of the non-domiciled population dictates that they will face more stress, thus seriously affecting their physical and mental health and quality of life [48].

This study also has some limitations. First, the data in this study were cross-sectional and therefore causal relationships between demographic characteristics and health status of older adults could not be obtained. In addition, some of the health indicators were used as self-reported data, which may be subject to reporting bias and require verification of their veracity with objective and accurate health indicators.

\section{Conclusion}

The health status of older adults needs to be determined by multiple dimensional health indicators. Through latent class analysis, this study identified three health latent classes with heterogeneity among Chinese older adults using multidimensional health indicators, and also found that selected demographic characteristics were associated with different health latent classes. Assessing health heterogeneity among older adults and its demographic influences provides a basis for policy development and clinical decision making to address the complex health issues of the Chinese elderly population.

\section{Declarations}

\section{Ethics approval and consent to participate}

Not applicable

\section{Consent for publication}

Not applicable 
Availability of data and materials

The datasets used and/or analyzed during the current study are available from the first author on reasonable request.

\section{Competing Interest}

The authors declare no conflict of interest.

\section{Funding}

This research was funded by Grant from Natural Science Foundation of Guangdong Province of China, grant number 2020A151501134.

\section{Authors' Contributions}

$\mathrm{YH}, \mathrm{ZW}$ contributed equally to the conception of the study. Design of the work: $\mathrm{YH}, \mathrm{ZW}$. Data cleaning and data analysis: YH. Discussion and interpretation of results: ZW. Critical revision of the first draft: ZL, BL. Funding acquisition: BL. All authors have read and approved the manuscript.

\section{Acknowledgments}

The authors thank the CHARLS research team and all respondents for their contribution.

\section{References}

1. Wang J, Wang Y, Cai H, Zhang J, Pan B, Bao G, Guo T. Analysis of the status quo of the Elderly's demands of medical and elderly care combination in the underdeveloped regions of Western China and its influencing factors: a case study of Lanzhou. BMC GERIATR. 2020, 20(1):338. doi:10.1186/s12877-020-01616-6.

2. Tsutsui T. Implementation process and challenges for the community-based integrated care system in Japan. INT J INTEGR CARE. 2014, 14:e2. doi:10.5334/ijic.988.

3. Salive ME. Multimorbidity in older adults. EPIDEMIOL REV. 2013, 35:75-83. doi: 10.1093/epirev/mxs009.

4. Lafortune L, Béland F, Bergman $H$, Ankri J. Health status transitions in community-living elderly with complex care needs: a latent class approach. BMC GERIATR 2009, 9:6. doi: 10.1186/1471-2318-9-6.

5. Yang L, Song LJ. The Trajectory of Multi-dimensional Health Indicators of Elderly Health Change:Evidence from CLHLS 2002囚2014 Longitudinal Data. Northwest Population Journal. 2020, 41(04):72-89.

6. $\mathrm{Ng} \mathrm{CW}$, Luo $\mathrm{N}$, Heng BH. Health status profiles in community-dwelling elderly using self-reported health indicators: a latent class analysis. QUAL LIFE RES .2014, 23(10):2889-2898. doi:10.1007/s11136-014-0723-7. 
7. Ye L, Luo J, Shia B, Fang Y. Multidimensional health groups and healthcare utilization among elderly Chinese: Based on the 2014 CLHLS dataset. INT J ENV RES PUB HE .2019, 16(20):3884. doi:10.3390/ijerph16203884.

8. Looman WM, Fabbricotti IN, Blom JW, Jansen A, Lutomski JE, Metzelthin SF, Huijsman R. The frail older person does not exist: development of frailty profiles with latent class analysis. BMC GERIATR. 2018, 18(1):84. doi:10.1186/s12877-018-0776-5.

9. Kim G, Chiriboga DA, Jang Y, Lee S, Huang CH, Parmelee P. Health status of older Asian Americans in California. J AM GERIATR SOC. 2010, 58(10):2003-2008. doi:10.1111/j.1532-5415.2010.03034.x.

10. Boume PA, Mcgrowder DA. Health status of patients with self-reported chronic diseases in Jamaica. North American Journal of Medical Sciences. 2009, 1(7):356-364. doi: 10.4297/najms.2009.7356.s

11. Lafortune L, Béland F, Bergman H, Ankri J. Health State Profiles and Service Utilization in Community-Living Elderly. MED CARE. 2009, 47(3):286-294.doi: 10.1097/MLR.0b013e3181894293.

12. Martin P, Gondo Y, Arai Y, Ishioka Y, Johnson MA, Miller LS, Woodard J, Poon LW, Hirose N. Cardiovascular health and cognitive functioning among centenarians: a comparison between the Tokyo and Georgia centenarian studies. INT PSYCHOGERIATR. 2019, 31(4):455. doi:10.1017/S1041610218001813.

13. Kushida O, Moon J, Matsumoto D, Yamasaki N, Takatori K. Eating Alone at Each Meal and Associated Health Status among Community-Dwelling Japanese Elderly Living with Others: A CrossSectional Analysis of the KAGUYA Study. NUTRIENTS. 2020, 12(9):2805. doi:10.3390/nu12092805.

14. Chen C, Liu GG, Shi QL, Sun Y, Zhang H, Wang MJ, Jia HP, Zhao YL, Yao Y. Health-related quality of life and associated factors among oldest-old in China. The journal of nutrition, health \& aging. 2020, 24(3):330-338. doi:10.1007/s12603-020-1327-2.

15. Wild B, Heider D, Schellberg D, Böhlen F, Schöttker B, Muhlack DC, König H, Slaets J. Caring for the elderly: A person-centered segmentation approach for exploring the association between health care needs, mental health care use, and costs in Germany. PLOS ONE. 2019, 14(12):e226510. doi:10.1371/journal.pone.0226510.

16. Engelman M, Jackson $\mathrm{H}$. Gradual Change, Homeostasis, and Punctuated Equilibrium: Reconsidering Patterns of Health in Later Life. DEMOGRAPHY. 2019, 56(6):2323-2347. doi:10.1007/s13524-01900826-x.

17. Kongsted A, Nielsen AM. Latent Class Analysis in health research. J PHYSIOTHER. 2017,63(1):55-58. doi:10.1016/j.jphys.2016.05.018.

18. Muthén B, Muthén LK. Integrating person-centered and variable-centered analyses: Growth mixture modeling with latent trajectory classes. Alcoholism: Clinical and experimental research. 2000, 24(6):882-891.

19. Collins LM, Lanza ST. Latent Class and Latent Transition Analysis: With Applications in the Social, Behavioral, and Health Sciences: Latent class and latent transition analysis; 2010.

20. Rely K, Vargas-Chanes D, García-Peña C, Salinas-Escudero G, Gutiérrez-Robledo L, Wong R. Multidimensional dependency subgroups in community-dwelling older adults: A latent class 
analysis. Revista de la Universidad Industrial de Santander. Salud. 2020, 52(2):101-109. doi:10.18273/revsal.v52n2-2020004.

21. Bibiano A, de Lima SV, Da SMR. Factors associated with the use of health services by elderly men in Brazil: a cross-sectional study. BMC PUBLIC HEALTH. 2019, 19(1):859. doi:10.1186/s12889-0197232-0.

22. Smeets R, Elissen A, Kroese M, Hameleers N, Ruwaard D. Identifying subgroups of high-need, highcost, chronically ill patients in primary care: A latent class analysis. PLOS ONE. 2020, 15(1):e228103. doi:10.1371/journal.pone.0228103.

23. Morin RT, Insel P, Nelson C, Butters M, Bickford D, Landau S, Saykin A, Weiner M, Mackin RS, Project AD. Latent classes of cognitive functioning among depressed older adults without dementia. Journal of the International Neuropsychological Society: JINS. 2019, 25(8):811. doi:10.1017/S1355617719000596.

24. de la Torre Luque A, Cabello M, Lara E, de la Fuente J, Miret M, Sanchez Niubo A, Haro JM, Ayuso Mateos JL. Functioning profiles in a nationally representative cohort of Spanish older adults: A latent class study. HEALTH SOC CARE COMM .2020, 28(6):2190-2198. doi:10.1111/hsc.13031.

25. Zhao Y, Hu Y, Smith JP, Strauss J, Yang G. Cohort profile: the China Health and Retirement Longitudinal Study (CHARLS). INT J EPIDEMIOL. 2014, 43(1):61-68. doi:10.1093/ije/dys203.

26. Katz SC, Ford AB, Moskowitz RW, Jackson BA, Jaffe MW. Studies of Illness in the Aged. The Index of Adl: A Standardized Measure of Biological and Psychosocial Function. Journal of the American Medical Association. 1963, 185(12):914-919. doi:10.1001/jama.1963.03060120024016.

27. Silverstein $\mathrm{M}$, Gong $\mathrm{CH}$, Kendig $\mathrm{H}$. Perceived availability of future care and depressive symptoms among older adults in China: evidence from CHARLS. BMC GERIATR. 2020, 20(1):31. doi:10.1186/s12877-020-1435-1.

28. Andresen EM, Malmgren JA, Carter WB, Patrick DL. Screening for depression in well older adults: evaluation of a short form of the CES-D (Center for Epidemiologic Studies Depression Scale). AM J PREV MED. 1994, 10(2):77-84.

29. Prince M, Acosta D, Ferri CP, Guerra M, Huang Y, Jacob KS, Llibre Rodríguez JJ, Salas A, Sosa AL, Williams JD. A brief dementia screener suitable for use by non-specialists in resource poor settingsthe cross-cultural derivation and validation of the brief Community Screening Instrument for Dementia. INT J GERIATR PSYCH. 2011, 26(9):899-907. doi:10.1002/gps.2622.

30. Muthén B, Muthén LK. Integrating Person-Centered and Variable-Centered Analyses: Growth Mixture Modeling With Latent Trajectory Classes. Alcoholism: Clinical and Experimental Research .2000, 24(6):882-891.

31. Hagenaars JA, McCutcheon AL. Applied latent class analysis: Cambridge University Press; 2002.

32. Lubke G, Muthén BO. Performance of factor mixture models as a function of model size, covariate effects, and class-specific parameters. Structural Equation Modeling: A Multidisciplinary Journal. 2007, 14(1):26-47. 
33. Strozza C, Pasqualetti P, Egidi V, Loreti C, Vannetti F, Macchi C, Padua L. Health profiles and socioeconomic characteristics of nonagenarians residing in Mugello, a rural area in Tuscany (Italy). BMC GERIATR. 2020, 20(1):289. doi:10.1186/s12877-020-01689-3.

34. Looman WM, Fabbricotti IN, Blom JW, Jansen A, Lutomski JE, Metzelthin SF, Huijsman R. The frail older person does not exist: development of frailty profiles with latent class analysis. BMC GERIATR. 2018, 18(1):84. doi:10.1186/s12877-018-0776-5.

35. Ye L, Luo J, Shia B, Fang Y. Multidimensional health groups and healthcare utilization among elderly Chinese: Based on the 2014 CLHLS dataset. INT J ENV RES PUB HE. 2019, 16(20):3884. doi:10.3390/ijerph16203884.

36. Browne JL, Ventura A, Mosely K, Speight J. 'I'm not a druggie, I'm just a diabetic': a qualitative study of stigma from the perspective of adults with type 1 diabetes. BMJ OPEN. 2014, 4(7):e005625. doi:10.1136/bmjopen-2014-005625.

37. Liu H, Yang Q, Narsavage GL, Yang C, Chen Y, Xu G, Wu X. Coping with stigma: the experiences of Chinese patients living with lung cancer. SpringerPlus. 2016, 5(1):1790. doi:10.1186/s40064-0163486-5.

38. de Vries HJ, de Groot R, van Brakel WH. Social participation of diabetes and ex-leprosy patients in the Netherlands and patient preference for combined self-care groups. Front Med (Lausanne). 2014, 1:21. doi:10.3389/fmed.2014.00021.

39. Franke T, Tong C, Ashe MC, McKay H, Sims-Gould J. The secrets of highly active older adults. J AGING STUD. 2013, 27(4):398-409. doi:10.1016/j.jaging.2013.09.003.

40. Xu LP. Correlation analysis between the current status and demand of living at home for diabetes patients. CHINESE JOURNAL OF MODERN NURSING. 2010(01):16-19.

41. Kuluski K, Peckham A, Gill A, Gagnon D, Wong-Cornall C, McKillop A, Parsons J, Sheridan N. What is Important to Older People with Multimorbidity and Their Caregivers? Identifying Attributes of Person Centered Care from the User Perspective. INT J INTEGR CARE. 2019, 19(3):4. doi:10.5334/ijic.4655.

42. Cumming BE, Henry WE. Growing Old, the Process of Disengagement: Growing old: the process of disengagement; 1961.

43. Guo XR. A study on the current status of chronic disease co-morbidity and major influencing factors among the elderly in China. Xiamen university. 2016

44. Tatangelo G, McCabe M, Campbell S, Szoeke C. Gender, marital status and longevity. MATURITAS. 2017, 100:64-69. doi:10.1016/j.maturitas.2017.03.002.

45. Liu L, Tian W, Yao $\mathrm{H}$. The heterogeneous health latent classes of elderly people and their sociodemographic characteristics in Taiwan. ARCH GERONTOL GERIAT .2014, 58(2):205-213. doi:10.1016/j.archger.2013.11.001.

46. Jiang Y, Zheng H, Zhao T. Socioeconomic Status and Morbidity Rate Inequality in China: Based on NHSS and CHARLS Data. INT J ENV RES PUB HE. 2019, 16(2):215. doi:10.3390/ijerph16020215.

47. Bai C. Study on the supply and effects of community health management service for urban-rural elderly under the background of pension combined with medical service: Evidence from CLHLS. 
Chinese Journal of Health Policy. 2020, 13(03):31-37.

48. Huang JY. Comparatively Studying on the Health-Related Pressure Between Local Residents and Migrants in Shanghai. Chinese Health Service Management. 2018, 35(02):144-146. 